EXTENDED REPORT

\title{
The Antioxidants in Prevention of Cataracts Study: effects of antioxidant supplements on cataract progression in South India
}

\author{
D C Gritz, M Srinivasan, S D Smith, U Kim, T M Lietman, J H Wilkins, B Priyadharshini, R K John, \\ S Aravind, N V Prajna, R Duraisami Thulasiraj, J P Whitcher
}

Br J Ophthalmol 2006;90:847-851. doi: 10.1136/bjo.2005.088104

\begin{abstract}
Aim: To determine if antioxidant supplements ( $\beta$ carotene and vitamins $C$ and $E$ ) can decrease the progression of cataract in rural South India.

Methods: The Antioxidants in Prevention of Cataracts (APC) Study was a 5 year, randomised, triple masked, placebo controlled, field based clinical trial to assess the ability of interventional antioxidant supplements to slow cataract progression. The primary outcome variable was change in nuclear opalescence over time. Secondary outcome variables were cortical and posterior subcapsular opacities and nuclear colour changes; best corrected visual acuity change; myopic shiff; and failure of treatment. Annual examinations were performed for each subject by three examiners, in a masked fashion. Multivariate modelling using a general estimating equation was used for analysis of results, correcting for multiple measurements over time.

Results: Initial enrolment was 798 subjects. Treatment groups were comparable at baseline. There was high compliance with follow up and study medications. There was progression in cataracts. There was no significant difference between placebo and active treatment groups for either the primary or secondary outcome variables.

Conclusion: Antioxidant supplementation with $\beta$ carotene, vitamins $C$ and $E$ did not affect cataract progression in a population with a high prevalence of cataract whose diet is generally deficient in antioxidants.
\end{abstract}

$\mathrm{T}$ he most common cause of blindness worldwide is unoperated cataracts. There is a disproportionate impact on blindness in the developing world, and access to quality cataract surgery has a strong role in the growing backlog of unoperated cataracts and increasing numbers of blind patients. ${ }^{1-5}$ In India, there may be earlier development and more rapid progression of cataracts than in other regions. ${ }^{6-8}$ Despite efforts to increase availability of high quality surgery with acceptable visual outcomes, there is still a growing backlog of patients who are blind from cataracts. If a practical, large scale intervention could slow the onset of cataract by 10 years, the need for cataract surgery would be decreased by $45 \% .{ }^{9}$ This would have a profound effect on the increasing backlog of patients who cannot be reached by surgery given the available resources.

A significant body of epidemiological evidence has been published regarding the potential role of antioxidants in the prevention of cataract. ${ }^{70-45}$ Although the majority of epidemiological studies have shown a positive correlation between higher dietary antioxidant intake and decreased cataract formation, ${ }^{71-27}$ conflicting conclusions exist. ${ }^{36-43}$ Also, as studies on $\beta$ carotene and lung cancer have shown, epidemiological evidence does not guarantee positive findings in interventional studies. ${ }^{46-49}$ This is a report of the results of the Antioxidants in Prevention of Cataract (APC) Study, an interventional trial conducted in south India. The APC study is the first prospective interventional trial for cataract prevention to take place in a developing country and includes baseline cataract evaluation.

\section{MATERIALS AND METHODS}

The APC study was a prospective, randomised, placebo control, triple masked, community based clinical trial to assess whether antioxidant supplements $(\beta$ carotene and vitamins $\mathrm{C}$ and $\mathrm{E}$ ) could slow the rate of cataract progression in south India. (A triple masked trial is when, in addition to the subjects and investigators being masked to the treatment groups, the biostatistician is also masked the treatment groups until analysis has been completed.) The study was based in five villages surrounding Madurai, Tamil Nadu, India, and was a collaborative project between the Aravind Eye Hospital in Madurai, India, and the Francis I Proctor Foundation for Research, in San Francisco, California. All of the investigations planned are in accordance with the guidelines of the Declaration of Helsinki. The study protocol was approved by the committee on human research at the University of California, San Francisco and the internal research board and ethics committee at the Aravind Eye Hospital. The methodology and baseline characteristics of the APC study have been described elsewhere in more detail. ${ }^{50}$

The study objective was to determine if antioxidant supplementation can slow the rate of cataract progression. All outcome variables compared the treatment and placebo groups. The primary outcome variable was mean change in nuclear opalescence over time, clinically graded at the slit lamp, using the Lens Opacification Classification System III (LOCS III). Secondary outcome variables were nuclear colour and cortical and posterior subcapsular opacities as clinically judged using the LOCS III, best corrected spectacle visual acuity, and failure of treatment. Failure of treatment was

Abbreviations: APC, antioxidants in prevention of cataract; BCVA, best corrected visual acuity; EDTRS, Early Treatment of Diabetic Retinopathy Study; GEE, general estimating equation; LOCS, Lens Opacification Classification System; RCT, randomised controlled trial; SES, socioeconomic status 
defined as cataract necessitating surgery, or best corrected visual acuity of 20/400 or worse.

Inclusion criteria were aged 35-50 years and best corrected visual acuity (BCVA) of 20/40 or better in both eyes and no history of diabetes mellitus, intraocular surgery, radiation therapy, corticosteroid therapy, or active use of vitamin supplements. The relatively young age was included because of the early progression of cataracts in south India, previously reported by others and observed in this study's pilot study. ${ }^{51}{ }^{52}$ Visual acuity was evaluated using the National Eye Institute Early Treatment of Diabetic Retinopathy Study logMAR (EDTRS) chart, using standard ETDRS methology. ${ }^{50}$ On eye examination, no evidence of significant traumatic or congenital cataract, active infectious keratitis, nor narrow anterior chamber angle could be present. A potential subject's random blood glucose testing could not be greater than $140 \mathrm{mg} / 100 \mathrm{dl}$.

Informed consent was obtained in the native language, Tamil. There was no monetary compensation for participation. Benefits of participation included free eye and medical care.

A field worker witnessed administration of active and identical appearing placebo tablets three times weekly. A single dose of active study medication contained vitamin C, $500 \mathrm{mg}$; vitamin A ( $\beta$ carotene from commercially grown algae in the all trans form with small amounts of other carotenoids like lycopene), $25000 \mathrm{IU}$ (15 mg); vitamin E (RRR- $\alpha$-tocopherol from soya oil with small amounts of other tocopherols), $400 \mathrm{IU}$. All tablets were manufactured by Vitaline Corporation, Ashland, Oregon, USA.

Slit lamp biomicroscopy was performed following dilatation. Each cataract was graded on nuclear colour and opalescence, cortical opacity, and posterior subcapsular opacity, in 0.1 units, with the grader referring to the LOCS III standard transparency as needed. Three ophthalmologists each graded cataracts in both eyes of all patients, masked to the other observer's scores. Two teams of three ophthalmologists graded the same subjects over the course of the study. Alternative ophthalmologist examiners were trained and available if needed, however the alternatives were not utilised.

Following enrolment, additional data were collected on socioeconomic status (SES), education, and history of exposure to tobacco, alcohol, sunlight, and cooking fuel smoke. A culturally sensitive food frequency questionnaire was administered three times during the course of the first year of the study to evaluate the diet.

\section{Statistical analysis}

Statistical comparison of baseline characteristics between treatment groups was made using a two sided $t$ test for continuous variables.

Analysis of the longitudinal data on LOCS III cataract grades was done by multivariate statistical modelling using a generalised estimating equation (GEE). The model used accounted for time related correlations in the data, allowing multiple measurements over time from the same individual. Analyses were conducted for right and left eyes separately.

Analysis of the treatment effect included adjustment for cofactors independently associated with cataract progression. Potential cofactors were evaluated using multivariate analysis and a cut off for inclusion in the treatment effect analysis was a $\mathrm{p}$ value of $<0.05$. These analyses were performed for the primary and secondary outcome LOCS III scores for the right and left eyes over time.

Analysis of change in logMAR visual acuity score was undertaken by comparing final to initial acuity. A statistical model accounting for correlation between eyes within an individual was used, permitting analysis of both eyes of all subjects within one statistical model.

Differences in the rate of cataract surgery between treatment groups were evaluated by univariate analysis.

\section{RESULTS}

Details on the baseline characteristics have been described in a separate publication..$^{50} \mathrm{~A}$ brief overview follows.

There were 4007 eligible subjects living in five main target villages; 954 subjects were screened for the study. Of those, 798 subjects were enrolled. Best corrected visual acuity worse than 20/40 was the most common factor leading to exclusion.

There were no statistically significant differences in baseline prevalence of potential cataract risk factors between the study groups. The baseline LOCS III scores for all cataract subtypes were comparable between the two groups. At baseline, slightly more than $73 \%$ of eyes had significant nuclear opalescence and almost $59 \%$ of eyes had significant nuclear colour changes (defined as a grade of $\geqslant 2.0$ on the LOCS III scale). Significant cataract, as per LOCS III definitions, of at least one of the cataract category was present in at least one eye of $79 \%$ of the subjects. Despite the degree of cataract present, $84.2 \%$ of right eyes had acuity of $20 / 20$ or better and a similar condition existed in left eyes. Over $84 \%$ of all eyes were within 1 dioptre of emmetropia. A detailed report of the baseline characteristics has been reported elsewhere. ${ }^{50}$

Table 1 Mean change per year in different LOCS III categories for all right eyes involved in the study, along with the associated $p$ values. Left eye results were similar

\begin{tabular}{|c|c|c|c|c|c|}
\hline LOCS III category & Age group* & $\begin{array}{l}\text { LOCS III score } \\
\text { mean change per } \\
\text { year placebo group }\end{array}$ & $\begin{array}{l}\text { LOCS III score } \\
\text { mean change per } \\
\text { year vitamin group }\end{array}$ & $\begin{array}{l}\text { Difference in slope } \\
\text { between groups }(95 \% \mathrm{Cl})\end{array}$ & p Value \\
\hline \multirow[t]{3}{*}{ Nuclear opalescence } & $35-39$ & 0.057 & 0.048 & $-0.009(-0.022$ to 0.005$)$ & 0.20 \\
\hline & $40-44$ & 0.086 & 0.086 & $0.000(-0.023$ to 0.022$)$ & 0.93 \\
\hline & $45-50$ & 0.101 & 0.131 & 0.031 (0.007 to 0.055$)$ & 0.01 \\
\hline \multirow[t]{3}{*}{ Nuclear colour } & $35-39$ & 0.07 & 0.063 & $-0.007(-0.019$ to 0.005$)$ & 0.26 \\
\hline & $40-44$ & 0.089 & 0.083 & $-0.006(-0.029$ to 0.014$)$ & 0.49 \\
\hline & $45-50$ & 0.107 & 0.125 & $0.018(-0.004$ to 0.042$)$ & 0.12 \\
\hline \multirow{3}{*}{ Cortical cataract } & $35-39$ & 0.026 & 0.025 & $-0.001(-0.001$ to 0.016$)$ & 0.92 \\
\hline & $40-44$ & 0.047 & 0.033 & $-0.014(-0.036$ to 0.010$)$ & 0.27 \\
\hline & $45-50$ & 0.078 & 0.07 & $-0.008(-0.037$ to 0.021$)$ & 0.57 \\
\hline \multirow{3}{*}{$\begin{array}{l}\text { Posterior subcapsular } \\
\text { cataract }\end{array}$} & $35-39$ & 0.006 & 0.004 & $-0.002(-0.012$ to 0.008$)$ & 0.68 \\
\hline & $40-44$ & 0.019 & 0.024 & $0.005(-0.021$ to 0.031$)$ & 0.70 \\
\hline & $45-50$ & 0.029 & 0.011 & $-0.018(-0.043$ to 0.023$)$ & 0.08 \\
\hline
\end{tabular}


Table 2 Mean spherical equivalent refractive error in the treatment and placebo groups over time

\begin{tabular}{|c|c|c|c|c|c|c|}
\hline \multirow{2}{*}{$\begin{array}{l}\text { Treatment } \\
\text { group }\end{array}$} & \multicolumn{6}{|c|}{ Mean spherical equivalent $(95 \% \mathrm{Cl})$} \\
\hline & Baseline & Year 1 & Year 2 & Year 3 & Year 4 & Year 5 \\
\hline $\begin{array}{l}\text { Placebo group } \\
\text { Vitamin group }\end{array}$ & $\begin{array}{l}-0.13 \\
(-0.19 \text { to }-0.06) \\
-0.07 \\
(-0.12 \text { to }-0.03)\end{array}$ & $\begin{array}{l}-0.22 \\
(-0.29 \text { to }-0.14) \\
-0.17 \\
(-0.21 \text { to }-0.11)\end{array}$ & $\begin{array}{l}-0.29 \\
(-0.37 \text { to }-0.21) \\
-0.16 \\
(-0.23 \text { to }-0.11)\end{array}$ & $\begin{array}{l}-0.21 \\
(-0.29 \text { to }-0.14) \\
-0.13 \\
(-0.19 \text { to }-0.08)\end{array}$ & $\begin{array}{l}-0.31 \\
(-0.40 \text { to }-0.21) \\
-0.17 \\
(-0.24 \text { to }-0.09)\end{array}$ & $\begin{array}{l}-0.26 \\
(-0.35 \text { to }-0.18) \\
-0.52 \\
(-0.34 \text { to }-0.18)\end{array}$ \\
\hline
\end{tabular}

Patients were excluded from this table if they were pseudophakic.) There were no significant differences between the two groups

Nine subjects reached the "failure of treatment" end point, three in the placebo group and six in the antioxidant group ( $p=0.51$ ).

Compliance with the study medication was excellent with $90.1 \%$ of subjects receiving $\geqslant 95 \%$ of the intended doses and an additional $6.1 \%$ of subjects receiving between $90 \%$ to $<95 \%$ of their intended doses. Only $0.8 \%$ of subjects received $<85 \%$ of intended tablets. There were no differences in compliance based on sex $(p=0.55)$ or age $(p=0.71)$ of subjects.

Risk factors associated with more rapid cataract progression included age, sex, sun exposure, random blood glucose over $140 \mathrm{mg} / \mathrm{dl}$ during the course of the study, and body mass index. Further details on these associations are the subject of a future paper.

There were no differences in cataract progression between treatment groups for the primary or any secondary outcome variables. Because there were differences in cataract progression according to age, the amount of progression was stratified by age at enrolment in table 1 .

Table 1 lists the details of the amount of progression in cataract over time for the primary and secondary LOCS III outcome variables. Some p values were less than 0.05 , with the placebo group having less progression compared to the treatment group. The absence of a consistent trend suggests that no treatment effect was present. When $\mathrm{p}$ was less than 0.05 , the differences between the groups in rate of cataract change was small and not clinically significant. Occasional small $p$ values were likely by chance because of multiple statistical comparisons. No significance was observed for any category when all age groups were combined. The 95\% confidence intervals for the amount of change per year between the two groups demonstrated that very small degrees of change in cataract could have been detected within the conditions of the study methodology and execution.

There were no differences in the change in visual acuity between the two groups $(p=0.8)$. The BCVA of the placebo group was a mean of 1.66 letters less (SD 4.96) at year 5 compared to baseline, while the BCVA of the treatment group was a mean of -1.64 letters less (SD 4.74) at year 5 compared to baseline.

There was no difference in the myopic shift observed between the two groups. Table 2 shows the mean myopic shift data.

\section{DISCUSSION}

The incidence of cataract in the developing world far surpasses the cataract surgical rate. ${ }^{53}$ Cataract incidence will increase as the world's population ages. The ability to meet the need for quality surgery will probably diminish further. ${ }^{54} 55$ Even if innovative ways of providing quality surgery to large populations can be developed, there will probably be a significant increase in cataract blindness. Finding preventive methods to delay the onset of cataract can help to narrow the gap between the incidence of cataract blindness and our ability to provide surgical treatment. The developing world has a disproportionate degree of cataract blindness. This results in a huge economic burden and loss of productivity. ${ }^{56}$ Thus, the development of a strategy for cataract prevention could have a great impact.

Epidemiological evidence indicates a possible role for antioxidants in the prevention of cataract. However, conflicting results exist between different epidemiological studies. Epidemiological study findings also do not necessarily equate with interventional measures.

At present, several studies have examined interventional cataract prevention. The majority, all in urban populations in developed countries, had negative results. ${ }^{32-35} 455758$ Despite the five trials with negative results, three trials had some potentially positive findings. Sperduto and associates examined patients at the end of two clinical trials in China. The Lixian studies showed a positive effect on nuclear cataract for two interventions, one with a combined multivitamin and mineral supplement and another trial with a riboflavin and niacin supplement. ${ }^{44}$ Chylack and associates performed a multicentre study in the United States and the United Kingdom. ${ }^{58}$ They observed a decrease in cataract progression with antioxidant supplements, particularly in patients from the United States, however, there was a large loss to follow up. Christen and associates found a positive effect of antioxidants on cataract in male physicians who were smokers at the onset of the 12 year clinical trial, but the effect did not hold for physicians who continued to smoke at the conclusion of the study. ${ }^{33}$ Subgroup analysis and multiple analyses cast doubt on whether there is a "real" effect of the intervention in this study.

The interventional studies performed to date demonstrate an apparent disconnect between epidemiological data and interventional studies. There are several possible reasons for this. Given the inconsistencies in the epidemiological data, it may be that dietary antioxidants, taken through fruits and vegetables, actually do not influence cataract progression as previously thought. The tendency for studies with positive findings to be published could potentially bias our body of knowledge. It is possible that the epidemiological data reflect a global effect of lifestyle that coincides with the dietary intake of antioxidants. It is also possible that substances within the food, other than $\beta$ carotene and vitamin $C$ and $E$, are responsible for decreasing cataract formation. Since this and other trials have been performed, the potential positive effect of other caratenoids, such as lutein and lycopene, have been the subject of epidemiological and laboratory studies.

The intervention doses of antioxidant vitamins being given in the APC study exceeded the US recommended minimum daily allowance of $5000 \mathrm{IU}$ for vitamin A, $60 \mathrm{mg}$ for vitamin $\mathrm{C}$, and 30 IU for vitamin E. The US recommended minimum daily allowance, however, is based on the minimal dose required to avoid vitamin deficiency diseases. The "optimal" dose of vitamins for "maximum health" has not been established. The doses of vitamins being given in this study are considered very safe. ${ }^{59-62}$ Much lower doses of $\beta$ carotene were used in this study compared to trials of $\beta$ carotene and lung cancer. ${ }^{46-49}$ In the lung cancer trials, the doses given were 3.1 (140 mg/week $){ }^{47} 3.9$ (350 mg/2 weeks) ${ }^{48}{ }^{49}$ and 4.7 
$(210 \mathrm{mg} / \text { week })^{46}$ times higher than those being given in this study.

The present study demonstrated no effect of the antioxidants $\beta$ carotene and vitamins $\mathrm{E}$ and $\mathrm{C}$ on cataract progression. Negative results of well performed studies are important. When assessing a study with negative findings it is important to examine the methodology.

Did this study provide adequate power to show a difference and avoid a $\beta$ type error (missing a positive finding because it was underpowered)? The initial enrolment was $143 \%$ of the original sample size estimate for a 3 year study. ${ }^{52}$ An interim analysis after 3 years resulted in the study being extended an additional 2 years. Given the results, the model used in this study worked very well and could have detected small differences between the study groups. The 95\% confidence intervals show that for all categories of cataract change, a difference between the groups in the range of only 0.05 LOCS III units would have been detected as "statistically significant," if the definition for significance were set at a p value of 0.05. Given the number of calculations performed and the interim analysis, that common arbitrary cut off of statistical significance would likely not be applicable. More importantly "clinical significance" would probably not hinge on a p value of 0.05 for a single analysis in this study.

The APC study is the first prospective, randomised, double masked, placebo controlled clinical trial performed specifically to assess the effect of antioxidant vitamins on cataract progression and performed in a developing country. The findings of this study, while negative, are important because previously it was not known whether intervention with vitamin C, E, and A supplements could decrease cataract formation in this setting. The fact that this study was negative in a population that may have been most likely to benefit from intervention (one in which the dietary antioxidant intake is low) should put to rest thoughts that $\beta$ carotene and vitamins $\mathrm{C}$ and $\mathrm{E}$, in isolation, can influence cataract progression. The model used to test this intervention was robust and could be applied to other interventions to assess cataract prevention. This study also demonstrates that a long term clinical trial performed in rural south India can have excellent follow up and robust data and results.

\section{ACKNOWLEDGEMENTS}

We gratefully acknowledge support from the Francis I Proctor Foundation's South Asia Research Fund; Aravind Eye Hospital and Postgraduate Institute of Ophthalmology, Madurai, India; Lions Aravind Institute of Community Ophthalmology, Madurai, India; the Peierls Foundation; the Jack and DeLoris Lange Foundation; the Harper-Inglis Trust; and generous donations to the Proctor Foundation from individual patients.

We gratefully acknowledge the following members of the Data and Safety Monitoring Committee: Perumalsamy Namperumalsamy, MD, Aravind Eye Hospital, Madurai, Tamil Nadu, India; KV Santha, MD, Aravind Eye Hospital, Madurai, Tamil Nadu, India; Stephen D McLeod, MD, Francis I Proctor Foundation for Research in Ophthalmology and the Department of Ophthalmology, University of California, San Francisco, San Francisco, CA, USA; Paul S Lietman, MD, PhD, Department of Medicine, Pharmacology, Molecular Science, and Pediatrics, Johns Hopkins University, Baltimore, MD, USA; and Sivakumar Rathinam, MD, Aravind Eye Hospital, Madurai, Tamil Nadu, India.

\section{Authors' affiliations}

D C Gritz, T M Lietman, J P Whitcher, Francis I Proctor Foundation for Research in Ophthalmology and the Department of Ophthalmology, University of California San Francisco, San Francisco, CA, USA D C Gritz, The Permanente Medical Group, Oakland and Richmond Kaiser Permanente Medical Centers and Department of Research, Oakland, CA, USA

M Srinivasan, U Kim, S Aravind, N V Prajna, R D Thulasiraj, Aravind Eye Hospital, Madurai, Tamil Nadu, India
S D Smith, Cole Eye Institute, The Cleveland Clinic Foundation, Cleveland, $\mathrm{OH}$, USA

J H Wilkins, Casey Eye Institute, Oregon Health Sciences University and the Lions Eye Bank of Oregon, Portland, OR, USA

B Priyadharshini, Orbis International, New Dehli, India

R K John, Delve Data Systems, Coimbatore, India

Conflicts of interest: none.

\section{REFERENCES}

1 Thylefors B, Negrel AD, Pararajasegaram R. Epidemiologic aspects of global blindness prevention. Curr Opin Ophthalmol 1992;3:824-34.

2 Thylefors B. Present challenges in the global prevention of blindness. Aust N Z J Ophthalmol 1992;20:89-94.

3 Bourne RR, Dineen B, Modasser AS, et al. The National Blindness and Low Vision Prevalence Survey of Bangladesh: research design, eye examination methodology and results of the pilot study. Ophthalmic Epidemiol 2002;9:119-32.

4 Ho VH, Schwab IR. Social economic development in the prevention of global blindness. Br J Ophthalmol 2001;85:653-7.

5 Lewallen S, Courtright $P$. Blindness in Africa: present situation and future needs. Br J Ophthalmol 2001;85:897-903.

6 Netland PA. Age of patients with cataracts in India [letter; comment]. Arch Ophthalmol 1992;110:597-8.

7 Mohan M, Sperduto RD, Angra SK, et al. India-US case-control study of agerelated cataracts. The India-US Case-Control Study Group. Arch Ophthalmol 1989; 107:670-6.

8 Wong TY. Cataract extraction rates among Chinese, Malays, and Indians in Singapore: a population-based analysis. Arch Ophthalmol 2001;119:727-32.

9 Kupfer C. Bowman Lecture. The conquest of cataract: a global challenge, Trans Ophthalmol Soc UK 1984;104:1-10.

10 The Italian-American Cataract Study Group. Risk factors for age-related cortical, nuclear, and posterior subcapsular cataracts. Am J Epidemiol $1991 ; 133: 541-53$

11 Jacques PF, Chylack LT Jr, McGandy RB, et al. Antioxidant status in persons with and without senile cataract. Arch Ophthalmol 1988;106:337-40.

12 Jacques PF, Hartz SC, Chylack LT Jr, et al. Nutritional status in persons with and without senile cataract: blood vitamin and mineral levels. Am J Clin Nutr 1988;48:152-8.

13 Jacques PF, Chylack LT Jr. Epidemiologic evidence of a role for the antioxidant vitamins and carotenoids in cataract prevention. Am J Clin Nutr 1991;53(Suppl):352S-5S

14 Jacques PF, Taylor A, Hankinson SE, et al. Long-term vitamin C supplement use and prevalence of early age-related lens opacities. Am J Clin Nutr 1997;66:911-16.

15 Hankinson SE, Stampfer MJ, Seddon JM, et al. Nutrient intake and cataract extraction in women: a prospective study. BMJ 1992;305:335-9.

16 Chasan-Taber L, Willett WC, Seddon JM, et al. A prospective study of carotenoid and vitamin $A$ intakes and risk of cataract extraction in US women. Am J Clin Nutr 1999;70:509-16.

17 Knekt $P$, Heliovaara $M$, Rissanen $A$, et al. Serum antioxidant vitamins and risk of cataract. BMJ 1992;305:1392-4.

18 Leske MC, Chylack LT Jr, Wu SY. The Lens Opacities Case-Control Study. Risk factors for cataract. Arch Ophthalmol 1991;109:244-51.

19 Leske MC, Wu SY, Hyman L, et al. Biochemical factors in the lens opacities. Case-control study. The Lens Opacities Case-Control Study Group. Arch Ophthalmol 1995;113:1113-19.

20 Mares-Perlman JA, Klein BE, Klein R, et al. Relation between lens opacities and vitamin and mineral supplement use. Ophthalmology 1994;101:315-25.

21 Mares-Perlman JA, Brady WE, Klein BE, et al. Diet and nuclear lens opacities. Am J Epidemiol 1995; 141:322-34.

22 Robertson JM, Donner AP, Trevithick JR. Vitamin E intake and risk of cataracts in humans. Ann N Y Acad Sci 1989;570:372-82.

23 Seddon JM, Christen WG, Manson JE, et al. The use of vitamin supplements and the risk of cataract among US male physicians. Am J Public Health 1994;84:788-92.

24 Simon JA, Hudes ES. Serum ascorbic acid and other correlates of selfreported cataract among older Americans. J Clin Epidemiol 1999;52:1207-11.

25 Kuzniarz M, Mitchell P, Cumming RG, et al. Use of vitamin supplements and cataract: the Blue Mountains Eye Study. Am J Ophthalmol 2001;132:19-26.

26 Jacques PF, Chylack LT Jr, Hankinson SE, et al. Long-term nutrient intake and early age-related nuclear lens opacities. Arch Ophthalmol 2001;119:1009-19.

27 Gale CR, Hall NF, Phillips DI, et al. Plasma antioxidant vitamins and carotenoids and age-related cataract. Ophthalmology 2001;108:1992-8.

28 Delcourt C, Carriere I, Delage $M$, et al. Associations of cataract with antioxidant enzymes and other risk factors: the French Age-Related Eye Diseases (POLA) Prospective Study. Ophthalmology 2003;1 10:2318-26.

29 Valero MP, Fletcher AE, De Stavola BL, et al. Vitamin C is associated with reduced risk of cataract in a Mediterranean population. J Nutr 2002;132:1299-306

30 Christen WG, Liu S, Schaumberg DA, et al. Fruit and vegetable intake and the risk of cataract in women. Am J Clin Nutr 2005;81:1417-22.

31 Moeller SM, Taylor A, Tucker KL, et al. Overall adherence to the dietary guidelines for Americans is associated with reduced prevalence of early agerelated nuclear lens opacities in women. J Nutr 2004;134:1812-19. 
32 McNeil JJ, Robman L, Tikellis G, et al. Vitamin E supplementation and cataract: randomized controlled trial. Ophthalmology 2004;11 1:75-84.

33 Christen WG, Manson JE, Glynn RJ, et al. A randomized trial of beta carotene and age-related cataract in US physicians. Arch Ophthalmol 2003;121:372-8.

34 Christen W, Glynn R, Sperduto R, et al. Age-related cataract in a randomized trial of beta-carotene in women. Ophthalmic Epidemiol 2004;11:401-12.

35 Olmedilla B, Granado F, Blanco I, et al. Lutein, but not alpha-tocopherol, supplementation improves visual function in patients with age-related cataracts: a 2-y double-blind, placebo-controlled pilot study. Nutrition 2003;19:21-4.

36 Chasan-Taber L, Willett WC, Seddon JM, et al. A prospective study of vitamin supplement intake and cataract extraction among US women. Epidemiology 1999; 10:679-84

37 Leske MC, Chylack LT Jr, He Q, et al. Antioxidant vitamins and nuclear opacities: the longitudinal study of cataract. Ophthalmology 1998; 105:831-6.

38 Lyle BJ, Mares-Perlman JA, Klein BE, et al. Antioxidant intake and risk of incident age-related nuclear cataracts in the Beaver Dam Eye Study. Am J Epidemiol 1999;149:801-9.

39 Lyle BJ, Mares-Perlman JA, Klein BE, et al. Serum carotenoids and tocopherols and incidence of age-related nuclear cataract. Am J Clin Nutr 1999;69:272-7.

40 Mares-Perlman JA, Brady WE, Klein BE, et al. Serum carotenoids and tocopherols and severity of nuclear and cortical opacities. Invest Ophthalmol Vis Sci 1995;36:276-88.

41 Nadalin G, Robman LD, McCarty CA, et al. The role of past intake of vitamin E in early cataract changes. Ophthalmic Epidemiol 1999;6:105-12.

42 Teikari JM, Rautalahti M, Haukka J, et al. Incidence of cataract operations in Finnish male smokers unaffected by alpha tocopherol or beta carotene supplements. J Epidemiol Commun Health 1998;52:468-72.

43 Vitale S, West S, Hallfrisch J, et al. Plasma antioxidants and risk of cortical and nuclear cataract. Epidemiology 1993;4:195-203.

44 Sperduto RD, Hu TS, Milton RC, et al. The Linxian cataract studies. Two nutrition intervention trials. Arch Ophthalmol 1993;111:1246-53.

45 Teikari JM, Virtamo J, Rautalahti M, et al. Long-term supplementation with alpha-tocopherol and beta-carotene and age-related cataract. Acta Ophthalmol Scand 1997;75:634-40.

46 Omenn GS, Goodman GE, Thornquist MD, et al. Effects of a combination of beta carotene and vitamin $A$ on lung cancer and cardiovascular disease. N Engl J Med 1996;334:1150-5.
47 The Alpha-Tocopherol Beta-Carotene Cancer Prevention Study Group. The effect of vitamin $\mathrm{E}$ and beta-carotene on the incidence of lung cancer and other cancers in male smokers. N Engl J Med 1994;330:1029-35.

48 Cook NR, Le IM, Manson JE, et al. Effects of beta-carotene supplementation on cancer incidence by baseline characteristics in the Physicians' Health Study (United States). Cancer Causes Control 2000;11:617-26.

49 Lee IM, Cook NR, Manson JE, et al. Beta-carotene supplementation and incidence of cancer and cardiovascular disease: the Women's Health Study. J Natl Cancer Inst 1999:91:2102-6.

50 Gritz DC, Srinivasan M, Smith SD, et al. Methodology and baseline data of the Antioxidants in Prevention of Cataracts (APC) Study. Ophthalmic Epidemiol 2006;(in press).

51 Nirmalan PK, Krishnadas R, Ramakrishnan R, et al. Lens opacities in a rural population of southern India: the Aravind Comprehensive Eye Study. Invest Ophthalmol Vis Sci 2003;44:4639-43.

52 Srinivasan $M$, Rahmathullah R, Blair CB, et al. Cataract progression in India. Br J Ophthalmol 1997;81:896-900.

53 Dandona L, Dandona R, Naduvilath TJ, et al. Population-based assessment of the outcome of cataract surgery in an urban population in southern India. Am J Ophthalmol 1999;127:650-8.

54 Kalache A, Keller I. The greying world: a challenge for the twenty-first century. Sci Prog 2000;83(Pt 1):33-54

55 Shrestha LB. Population aging in developing countries. Health Aff (Millwood) 2000;19:204-12.

56 Shamanna BR, Dandona L, Rao GN. Economic burden of blindness in India. Indian J Ophthalmol 1998;46:169-72.

57 The Age-Related Eye Disease Study Group. A randomized, placebocontrolled, clinical trial of high-dose supplementation with vitamins $C$ and $E$ and beta carotene for age-related cataract and vision loss: AREDS report no 9. Arch Ophthalmol 2001;119:1439-52.

58 Chylack LT Jr, Brown NP, Bron A, et al. The Roche European American Cataract Trial (REACT): a randomized clinical trial to investigate the efficacy of an oral antioxidant micronutrient mixture to slow progression of age-related cataract. Ophthalmic Epidemiol 2002;9:49-80.

59 Bendich A, Machlin L. Safety of oral intake of vitamin E. Am J Clin Nutr 1988:48:612-19.

60 Diplock AT. Safety of antioxidant vitamins and beta-carotene. Am J Clin Nutr 1995:62(6 Suppl):1510S-16S.

61 Meydani SN, Meydani M, Blumberg JB, et al. Assessment of the safety of supplementation with different amounts of vitamin $\mathrm{E}$ in healthy older adults. Am J Clin Nutr 1998;68:311-18.

62 Meyers DG, Maloley PA, Weeks D. Safety of antioxidant vitamins. Arch Intern Med 1996;156:925-35. 